\title{
PARA UNA TIPOLOGÍA DEL REANÁLISIS MORFOLÓGICO
}

\author{
IVÁN IGARTUA \\ Universidad del País Vasco \\ $U P V / E H U$
}

\section{RESUMEN}

En este artículo se propone una tipología nueva, que aspira a ser completa, del reanálisis morfológico, tomando en cuenta no solo los fenómenos derivativos, sino también los flexivos. Con arreglo a esta propuesta se pueden identificar cuatro tipos principales de reanálisis morfológico: la fusión afijal, la secreción afijal, la deafijación y la reafijación. Como indican los propios términos, el criterio de esta clasificación corresponde al comportamiento diacrónico de los afijos. Algunas de las clases mencionadas incluyen subtipos, que son analizados a lo largo del estudio y comparados con la tipología, más simple, de la resegmentación morfémica (pérdida, creación y desplazamiento de linde morfológica). Sobre la base de los datos examinados se pone en cuestión la noción de unidireccionalidad para esta clase de evoluciones, supuestamente orientadas siempre hacia el crecimiento afijal, toda vez que algunas alteraciones conducen al efecto inverso, la reducción afijal. Otra de las implicaciones teóricas del artículo es la que hace referencia a la autonomía del reanálisis en cuanto mecanismo de cambio morfológico no necesariamente sujeto a la acción previa de la analogía.

Palabras clave: reanálisis morfológico, resegmentación, analogía, tipología diacrónica, linde morfológica.

\section{ABSTRACT}

This article proposes a renewed and comprehensive typology of morphological reanalysis, which takes into consideration not only derivational, but also inflectional phenomena. According to this proposal, four main types of morphological reanalysis can be identified, namely: affix fusion, affix secretion, deaffixation and reaffixation. As terms themselves reveal, the criterion for this classification corresponds to the diachronic behavior of affixes. Some of these classes include various subtypes, which are discussed throughout the article and compared to the simple typology of morpheme resegmentation (loss, creation and displacement of morpheme boundaries). On the basis of the data examined here the claim of unidirectionality for this kind of morphological evolutions (always towards affix growth) is seriously challenged, since some developments can lead to affix reduction. Another theoretical implication of the article is the autonomous perspective on reanalysis as a mechanism of morphological change not necessarily depending upon analogy's previous action.

Key Words: morphological reanalysis, resegmentation, analogy, diachronic typology, morpheme boundary. 


\section{INTRODUCCIÓN ${ }^{1}$}

Los mecanismos de alteración morfológica en las lenguas naturales pueden reducirse a tres operaciones: analogía, reanálisis y préstamo. Este último se debe al contacto entre lenguas, por lo que se trata de un factor de influencia morfológica externa. La analogía, por su parte, ha sido tradicionalmente dividida en la llamada «nivelación paradigmática», cuyo resultado es la eliminación de alternancias morfofonológicas en el seno de los paradigmas flexivos, y la «extensión analógica», que trasvasa morfemas o patrones morfológicos de una parcela gramatical a otra. En un trabajo reciente Garrett 2008 ha unido estos dos tipos clásicos de analogía en uno solo, la extensión analógica, puesto que, a su juicio, la nivelación paradigmática no es sino la extensión de un paradigma morfotácticamente regular a costa de los paradigmas que presentan alternancias de este tipo. Esa misma fusión de fenómenos tradicionalmente diferenciados fue defendida anteriormente por Deutscher 2001, para quien la extensión y la nivelación son igualmente casos de extensión. En una línea de razonamiento similar se sitúa la propuesta a su vez anterior de Croft 2000, p. 154; 2006, quien identifica en el fenómeno general de la «intraferencia» (correlato interno de la interferencia de sistemas en contacto) el motivo que da explicación conjunta a la extensión analógica y a la nivelación paradigmática. De aceptarse la reducción propuesta primero por Croft y Deutscher, y luego por Garrett, el paralelismo entre los mecanismos de cambio morfológico y los de cambio sintáctico, tal y como estos son clasificados por Harris y Campbell 1995, resultaría completo (como quería, por ejemplo, Deutscher 2001)². En suma, tomando en cuenta factores tanto internos como externos, las modificaciones estructurales y formales en ambas parcelas de la gramática vendrían determinadas por la acción de los tres mecanismos ya mencionados: reanálisis, extensión y, en su caso, préstamo.

Pese a ello, la separación de la analogía o extensión y el reanálisis ha sido discutida recientemente por varios autores (v. § 2) desde una perspectiva en general sintáctica. Algunos consideran el vínculo entre ambos mecanismos como una relación de dependencia: el reanálisis es un cambio estructural inducido y, por tanto, siempre predeterminado por la acción de la analogía (Fischer 2007, p. 48, n. 7). A la circunstancia de no ver en el reanálisis un mecanismo de cambio inde-

\footnotetext{
${ }^{1}$ La presente investigación se enmarca en el proyecto FFI2008-04009, financiado por el Ministerio de Ciencia e Innovación. Expreso aquí mi agradecimiento a José Andrés Alonso de la Fuente, Joaquín Gorrochategui y Joseba Lakarra por su paciente lectura del artículo y sus comentarios, que a buen seguro no habré sabido aprovechar como se merecían.

${ }^{2}$ Peyraube 2002 extiende el esquema tripartito inspirado en el trabajo de Harris y Campbell al ámbito morfosintáctico en general.
} 
pendiente otros investigadores añaden la conveniencia de desgranar los procesos de alteración básicos que cabe discernir en él (especialmente en el reanálisis sintáctico, cf. De Smet 2009). Con motivo de estas reinterpretaciones del papel del reanálisis parece necesaria también una reconsideración del mismo desde el punto de vista morfológico, con el fin de determinar el carácter autónomo o no del reanálisis con respecto al otro mecanismo fundamental de cambio morfológico interno, la analogía.

El presente artículo busca en esencia una clasificación lo más completa posible de los diversos tipos de reanálisis morfológico que pueden identificarse. A su vez, el estudio pormenorizado de esos tipos de reanálisis acarrea consecuencias de índole teórica en torno a la naturaleza del reanálisis en tanto mecanismo de cambio morfológico. A diferencia de la aglutinación entendida como proceso morfológico, que no será examinada aquí ${ }^{3}$, el reanálisis es una fuente paradigmática de renovación de segmentos morfológicos (cf. Haspelmath 1995, p. 1), basada en la relación entre formas que presentan similitudes estructurales. Debido a la presencia de diferencias constitutivas, la comparación de tales formas muestra que la segmentación en morfemas puede experimentar variaciones posicionales que están en la raíz del reanálisis. Puesto que se trata de un término con cierta tradición en la lingüística actual, en las líneas que siguen el reanálisis será caracterizado en primer lugar desde el punto de vista terminológico y conceptual (\$2); posteriormente, y a partir de las diferencias observables en los cambios morfológicos debidos a reanálisis, ofreceré una clasificación tipológica -formalmente motivada $(\S 3)$ - del reanálisis para el ámbito de la morfología (\$ 4); a continuación, y tras analizar las relaciones entre dos tipos de clasificación (el de la resegmentación y el del reanálisis, §5), dedicaré a la llamada secreción un examen algo más detallado, dado que constituye el tipo de reanálisis más confuso ( $\$ 6$ y 7 ); finalmente $(\S 8)$, y antes de alcanzar las conclusiones, trataré de evaluar el carácter supuestamente universal del crecimiento afijal en tanto resultado de los procesos de reanálisis morfológico. A lo largo de la exposición los datos que se estudian harán posible a su vez la discriminación de los procesos de analogía y de reanálisis, aspecto necesario para la consideración del reanálisis como mecanismo autónomo de cambio morfológico.

\footnotetext{
${ }^{3}$ Aunque el mecanismo de la aglutinación produce asimismo alteraciones en la morfología (rum. lupul 'lobo (det.)' < lat. lupus ille, vasc. gizonarekin 'con el hombre' < * gizonare(n) kide(a)n 'en compañía del hombre'), se trata de un medio de creación morfológica externo a la propia morfología, definido por el recorrido de la sintaxis a la morfología que realizan las unidades afectadas por el cambio. Es, por tanto, más un mecanismo sintagmático de morfologización (a través de la univerbación) que un medio de transformación propiamente morfológico (v. Joseph y Janda 1988, p. 197; Norde 2009, p. 78).
} 


\section{TÉRMINOS, DEFINICIONES Y USOS}

El concepto más extendido de reanálisis refiere este proceso a una reinterpretación estructural (de cualquier construcción) que no resulta inmediatamente visible en el plano formal ${ }^{4}$, de modo que el reanálisis es detectable solo cuando sus efectos se extienden a otras unidades en las que no se daban las condiciones requeridas para el nuevo análisis (condiciones vinculadas casi siempre a la ambigüedad constructiva o, si no, a la opacidad; v. infra). La definición sirve, por supuesto, tanto para los cambios morfológicos como para los sintácticos. Con el término reanálisis compitió durante algún tiempo el llamado «metanálisis», empleado para designar en esencia el mismo proceso. No obstante, y aunque en los últimos tiempos es el término reanálisis el que se ha impuesto, en ocasiones el metanálisis se reserva para la resegmentación de la linde morfológica en contextos flexivos.

El estudio teórico pormenorizado de los procesos de reanálisis se remonta al menos al último cuarto del siglo XIX. En el ámbito de trabajo de la escuela de Kazán, encabezada en su día por el lingüista polaco Jan N. Baudouin de Courtenay, otro joven lingüista polaco, M. Kruszewski, identificó en la historia de las lenguas eslavas procesos recurrentes de reanálisis que él denominó absorciones. Tal y como la concebía Kruszewski 1880, la absorción conllevaba el desplazamiento de la frontera morfológica entre la base nominal y la desinencia. En el transcurso del cambio el morfema flexivo acaba por absorber la vocal temática, como ilustra el caso de esl. com. *ryb-a-mb 'peces' (dat. pl.) $\rightarrow{ }^{*} r y b-a m b$.

Entre los lingüistas próximos a la corriente neogramática encontramos también los primeros intentos de clasificación sistemática de los tipos de reanálisis, con sus consiguientes denominaciones. Los pioneros fueron H. Paul y K. Appel: el segundo recogió en 1881 ejemplos de lo que él llamaba «secreciones» $\mathrm{y}$ «excreciones». Entre los términos usuales dentro de la escuela de los neogramáticos para hacer referencia al reanálisis morfológico destaca, por su transparencia, el de Gliederungsverschiebung (cambio en la distribución).

En sus aproximaciones a los hechos de reanálisis Baudouin de Courtenay recurrió al uso del término pererazloženie, introducido por Bogorodickij 1915 y con un valor próximo al de la «resegmentación» (literalmente «re-descomposición»), para dar cuenta de la evolución que experimenta la flexión nominal en la historia de las lenguas eslavas, una evolución basada fundamentalmente en el oscurecimiento de la función primigenia de la vocal temática en las diversas clases flexivas.

\footnotetext{
${ }^{4}$ «A change in the structure of an expression or class of expressions that does not involve any immediate or intrinsic modification of its surface manifestation» (Langacker 1977, p. 58); v. también Timberlake 1977.
} 
La vocal, que en origen forma parte de la base nominal, es reinterpretada como segmento perteneciente a la desinencia nominal (es absorbida, como diría Kruszewski, por el morfema desinencial). La definición originaria de pererazloženie recoge esta direccionalidad del cambio: en palabras de Baudouin de Courtenay 1963 (1902), p. 25, el término hace referencia a la «reducción general de los temas nominales a favor de las terminaciones» (pogolovnoe sokraščenie osnov v pol'zu okončanij) ${ }^{5}$.

Pocos años después, Jespersen 1922 incluyó en su influyente monografía sobre el lenguaje datos y reflexiones en torno a los procesos de reanálisis y, en particular, a la clase de reanálisis que denominó secretion (v. acerca de ello Lindström 2004), un término ya utilizado por Appel para referirse a ejemplos de evolución morfológica similares a los que manejó el propio Jespersen (como en el caso de la reinterpretación de al. Menschen 'hombres' como Mensch-en).

En tiempos más recientes, se ha tendido a veces a separar el reanálisis sintáctico de la resegmentación morfológica, utilizada como término (Langacker 1977). Pero el unitarismo en la descripción parece favorecer el uso de reanálisis también para el mecanismo de resegmentación morfológica (con lo que este último concepto suele conformar el cuerpo de la definición del propio reanálisis). En el dominio sintáctico otros términos han sido empleados como sinónimos o han sido antecedentes del reanálisis, entre ellos restructuring, rebracketing o resetting (como en los estudios de D. Lightfoot).

Sin salirnos del terreno sintáctico, lo que hasta hace relativamente poco era considerado un mecanismo indudable de alteración estructural ha sido puesto en entredicho por diversos autores. Una primera crítica de la concepción recogida en el tratado de Harris y Campbell 1995 se debe a McDaniels 2003, quien desvela lo que en su opinión son las facetas más débiles de la noción de reanálisis: la delimitación confusa de los ámbitos de actuación del reanálisis y de la extensión, incluso el carácter superfluo del reanálisis en tanto que entraña la suposición de un cambio con anterioridad a su manifestación en la gramática. En su recentísima aportación a la discusión, De Smet 2009 considera que el reanálisis carece de fuerza explicativa porque, por un lado, su dependencia de la ambigüedad presenta lagunas de argumentación lógica y, por otro, el reanálisis supone la alteración de una estructura antigua por otra nueva sin que se especifique la fuente de esa nueva estructura. En opinión del autor (De Smet 2009, p. 1730, 1748 ss.), los fenómenos vinculados al reanálisis han de ser desmenuzados en pautas o mecanismos de cambio más elementales, como son la «incursión categorial» (enten-

\footnotetext{
${ }^{5} \mathrm{El}$ alcance del término ha sufrido, sin embargo, variaciones. En la actualidad pererazloženie se emplea para cualquier alteración de la división morfológica en el seno de una palabra (v. infra y también Vinogradov 1990, p. 370).
} 
dida como la extensión analógica de una construcción hacia el dominio de otra), el «cambio interno gradual» (extensión de las fronteras de una categoría en su aspecto semántico) y la «automatización», por la que una construcción adquiere paulatina autonomía (y tiende, por tanto, a ser almacenada en la memoria como un conjunto indivisible) con respecto a la estructura sintáctica que está en su origen. En cualquier caso, y aunque en su visión el reanálisis deja de ser un mecanismo particular de cambio sintáctico, este sigue teniendo relevancia como constelación de cambios básicos, entre los cuales la analogía ocupa un lugar determinante.

Dentro de los procesos de gramaticalización, el reanálisis suele ser considerado uno de los dos mecanismos principales de creación de nuevas formas gramaticales (el otro es la analogía; cf., por ejemplo, Norde 2009). Sin embargo, parte de los detractores de la teoría de la gramaticalización considera que fenómenos habitualmente explicados por medio de la cadena de gramaticalización son simplemente debidos a sucesivos reanálisis estructurales (Campbell 2001, cf. Elvira 2009, p. 206, n. 76; para el reanálisis en la gramaticalización de be going to v. asimismo Bybee 2006; Fischer 2008, p. 354; Garrett, 2012, pp. 66 ss.). Incluso algunas perspectivas sobre la gramaticalización, no necesariamente contrarias a la existencia de esta, ven en el reanálisis el mecanismo principal que da cuenta de los distintos cambios englobados en la cadena de gramaticalización (es la perspectiva que adoptan, por ejemplo, Hopper y Traugott 2003, p. 59) ${ }^{6}$. Los procesos inversos de desgramaticalización, menos frecuentes, también parten en general del reanálisis de formas situadas en contextos en buena medida ambiguos (Willis 2007; Norde 2009, pp. 143-151).

En cualquier caso, el reanálisis no resulta equiparable ni a la gramaticalización (Plank 2004) ni a la desgramaticalización: de hecho, la primera, por ejemplo, no siempre incluye procesos de reanálisis (Haspelmath 1998) y, en la concepción de Kiparsky 2005, constituye más bien el producto de una clase especial de analogía que el autor denomina non-exemplar based analogy (v. también Fischer 2008, p. 352 ss., 371; para la noción de gramaticalización como cambio esencialmente analógico, en cuyo marco el reanálisis pasa a ser mero epifenómeno, cf. también De Smet 2009, p. 1752).

El reanálisis tiene asimismo cabida en el terreno de la fonología. Los fenómenos de reasignación de unidades de realización fonética a distintos fonemas pueden ser interpretados como hechos de reanálisis. El llamado cambio «abductivo» (Andersen 1973) fue inicialmente ilustrado con fenómenos fonológicos y, si hemos de hacer caso a la crítica -por

\footnotetext{
${ }^{6}$ V. también Narrog 2007, p. 3: «both processes, grammaticalization and exaptation, can be regarded as the result of an even more powerful mechanism, namely reanalysis».
} 
lo demás, no siempre equitativa- de Deutscher 2002, la abducción en los casos tratados por Andersen no sería más que un ejemplo de reanálisis, para el que el término comúnmente utilizado resulta no solo suficiente, sino también más adecuado (para hacer justicia a la construcción teórica de Andersen habría que afirmar más bien que el reánalisis es un tipo posible de abducción; cf. Itkonen 2002, p. 413). Dado que la abducción ha sido relacionada con los procesos de adquisición de la lengua, también aquí ha encontrado uso la propia noción de reanálisis (Wanner 2006, p. 47).

Desde el punto de vista descriptivo, la referencialidad del reanálisis resulta en principio nítida: la condición previa para la actuación del dispositivo de modificación corresponde a la presencia de ambigüedad o bien de opacidad en la configuración estructural (cf. Harris y Campbell 1995, p. 72; Wanner 2006, p. 48), mientras que el propio reanálisis consiste en la reinterpretación de esa misma configuración sin consecuencias directas en el aspecto formal. Otra cosa es la capacidad explicativa que pueda atribuirse al reanálisis. Como indica Garret 2012, p. 53, «reanalysis per se has little explanatory force. Any number of reanalyses are imaginable, and many logically possible reanalyses fail to occur; reanalysis is moreover incapable on its own of explaining directional asymmetries. Therefore a mature research program should not only characterize structural reanalysis in specific cases but should also seek to understand what triggers it». Ello equivale a decir que la condición de ambigüedad previa -que alterna con la opacidad morfotáctica en el ámbito de la morfología (Koch 1996, p. 237) - no explica la acción del reanálisis, puesto que por sí sola resulta insuficiente para desencadenar el proceso (no toda situación de ambigüedad acarrea alteraciones debidas a reinterpretación estructural). De ahí que la atribución de innovaciones lingüísticas al mecanismo de reanálisis requiera en cada caso la exposición, allí donde resulta posible, de los factores que no solo facilitan, sino que además impulsan el cambio.

\section{El REANÁLISIS EN MORFOLOGÍA: PERSPECTIVAS FORMAL Y SEMÁNTICA}

Aunque definido como reinterpretación estructural de una secuencia, el reanálisis parece vinculado más al ámbito de lo formal que al semántico. Sin embargo, no por ello dejan de darse empleos del término orientados a este segundo polo. Frente a la perspectiva formal sobre el reanálisis en morfología, que se concentra fundamentalmente en la modificación de las fronteras morfológicas (la resegmentación), la perspectiva semántica parte de la función o valor gramatical de los morfemas para aplicar el mismo término a los casos de reutilización funcional de segmentos morfológicos conocida como exaptación (Lass 1990; 
1997, p. 317). En concreto, Narrog 2007 considera que la «exaptación», fenómeno inverso al de la gramaticalización -punto en cualquier caso discutible-, es producto de un proceso de reanálisis, es decir, de reinterpretación en este caso funcional de morfemas, durante el cual no suele mediar, por lo demás, ningún proceso de resegmentación. De hecho, la variación de linde morfológica no tiene relevancia alguna desde este punto de vista.

Una perspectiva mixta, aunque con cierto énfasis en el aspecto funcional, es la que aplica Croft 2000, cap. 5, en su clasificación de lo que denomina form-function reanalysis, para distinguirlo del reanálisis estructural. La división de los cambios en «hiperanálisis», «hipoanálisis», «metanálisis» y «criptoanálisis» se corresponde en todos los casos con reinterpretaciones funcionales de estructuras lingüísticas.

En el presente trabajo, en cambio, la perspectiva que se adopta a la hora de establecer los tipos de reanálisis morfológico es exclusivamente formal, por más que, al tratarse de segmentos morfológicos, en el cambio puedan resultar afectadas las relaciones entre el significante/signans y el significado/signatum (v. infra). Ello quiere decir, según se apuntaba antes, que los casos de reanálisis son reconocidos en la medida en que han supuesto alteración de las divisiones morfológicas de la palabra, lo cual supone atender principalmente al comportamiento diacrónico de los afijos de que constan las palabras morfológicamente complejas. Pero en la modificación de esas divisiones morfológicas o fronteras entre morfemas pueden verse involucrados tanto los significantes o signantia (y a veces, al menos en primera instancia, exclusivamente ellos) como los significados o signata (mediante una reasignación de valores entre los segmentos morfológicos existentes que deriva en una modificación posterior de los signantia). Por ello en la clasificación han de estar contempladas tanto una clase como otra de innovación (Andersen 1980, pp. 24-25).

La modificación segmental que se encuentra en la base del reanálisis puede ser, desde una perspectiva lógica, de tres tipos: supresión, creación o desplazamiento de fronteras morfológicas (en la tipología que aquí se propone a cada uno de ellos le corresponde una subclase o más de reanálisis). En una clasificación que parte de esas tres operaciones esenciales (Koch 1996, pp. 237-240) no tienen cabida, por tanto, fenómenos como el de la exaptación morfológica, interpretada como el reciclaje funcional de elementos morfológicos que han perdido su valor gramatical o que, sin haberlo perdido aún, lo modifican. La exaptación no implica resegmentación, que es el punto de referencia esencial para una clasificación de naturaleza formal, por lo que no puede ser incluida entre los tipos de reanálisis secuencial. Para favorecer una diferenciación terminológica máxima entre nociones que son de por sí 
distintas aunque cercanas, parecería conveniente referirse al reanálisis funcional como reinterpretación o refuncionalización, que es el contenido de la propia exaptación, y no como reanálisis, que apela en todo caso a la operación de volver a analizar, dividir o segmentar una secuencia determinada.

Aunque la resegmentación entraña, como se ha indicado, solo tres operaciones (supresión, creación o desplazamiento de linde morfológica), las diferencias entre los procesos y los resultados particulares de reanálisis conducen al establecimiento de más clases y subclases de alteración morfológica en el plano segmental. En el apartado siguiente se describen esos tipos de reanálisis y posteriormente $(\S 5)$ se trazan las relaciones entre las posibilidades de resegmentación y los tipos empíricos de reanálisis en la morfología.

\section{TIPOS DE REANÁLISIS MORFOLÓGICO}

Una tipología del reanálisis morfológico ha de estar fundamentada (dado que opera con segmentos morfológicos) en la relación entre las dos vertientes del signo lingüístico: el significante o los morfemas y el significado o los valores de los morfemas. Las transformaciones por reanálisis afectan a la relación entre ambos niveles: el reanálisis morfológico altera la secuencia estructural de la palabra y, por tanto, también afecta, aunque sea secundariamente, al vínculo entre los componentes del significado (sea léxico o gramatical), aunque no active cambios en el propio dominio semántico. En los casos más leves de reanálisis, la modificación atañe únicamente a la parte gramatical de la palabra, sin que la raíz o base resulten alterados. Los tipos principales de reanálisis morfológico que integran esta propuesta de clasificación conocen a su vez subclases en función de los segmentos afectados por el cambio.

El criterio principal de clasificación corresponde al carácter de las nuevas relaciones que se establecen entre significante y significado, es decir, atiende a la diversidad de resultados de los procesos de reanálisis morfológico. Estos pueden acabar en fusión, en secreción (separación), en desafijación o en reafijación de segmentos morfológicos. Tales son los tipos principales de reanálisis en el ámbito de la morfología cuando se contemplan desde una perspectiva esencialmente formal (v. supra, §3). La tipología que aquí se propone difiere significativamente de la clasificación, más limitada y menos general, que ofreció en su día Haspelmath 1995. Dos de los tipos de reanálisis establecidos por el autor son relacionados aquí con un solo resultado común (la fusión), mientras que el tercer y cuarto tipo de la nueva clasificación 
simplemente no aparecen representados en la de Haspelmath ${ }^{7}$. En el caso de la secreción, que sí figura en la propuesta anterior (aunque con un alcance excesivamente restringido), conviene distinguir, como se hará, varios subtipos, algunos de los cuales habían sido ya identificados por Jespersen 1922.

\subsection{Fusión afijal}

La fusión de segmentos morfológicos, proceso por el cual dos o más morfemas son reinterpretados como uno solo, presenta dos subtipos: el que Haspelmath 1995, p. 3, inspirado por Becker 1990, p. 48, denomina affix telescoping y la conglutinación. La diferencia entre ambos es de naturaleza más semántica que morfológica, puesto que en los dos procesos de reanálisis el afijo resultante aúna los segmentos de dos morfemas anteriores. En el caso del affix telescoping o afijación telescópica, un término al que había recurrido con anterioridad W. Mayerthaler, es la relación semántica entre la forma de base y la resultante (derivada de la amalgama de dos o más afijos) la que se extiende a los nuevos contextos morfológicos (aquellos precisamente que permiten hablar de la actuación previa del reanálisis), en tanto que en la conglutinación, la relación que se traslada a los nuevos contextos es la que se da entre el conjunto raíz o base + primer afijo y el resultado final, derivado de la amalgama de dos o más afijos. En el fenómeno de la afijación telescópica, el resultado sigue contando con las unidades de significado anteriormente repartidas en dos significantes, mientras que en la conglutinación, la fusión de segmentos morfológicos viene acompañada por la fusión (indistinción) de componentes semánticos (el primer afijo se integra formal y semánticamente en el segundo).

\subsubsection{Afijación telescópica}

En este subtipo de fusión afijal, el reanálisis consiste en la supresión de la frontera morfológica que anteriormente separaba dos afijos. Como ilustración de este proceso puede mencionarse la derivación en eslavo antiguo de blods 'pecado' $\rightarrow$ blodbnikb 'pecador' y de Kind

\footnotetext{
${ }^{7}$ La limitación de la propuesta clasificatoria de Haspelmath viene determinada, de un lado, por el conjunto de datos que integran su estudio, pertenecientes en su mayor parte al ámbito de la derivación (con escasa presencia de la flexión, cf. Haspelmath 1995, p. 19) y, de otro, por su interpretación excesivamente restrictiva de la noción de resegmentación, que no incluye las operaciones de supresión ni de creación de lindes morfológicas (Haspelmath 1995, pp. 25-26, n. 17), aunque, en este segundo aspecto, la posición del autor no es del todo coherente (al menos dos de los tipos de reanálisis que distingue implican supresión de linde).
} 
'niño' $\rightarrow$ Kindlein (dim.) en alemán (Haspelmath 1995, pp. 4-5). La inicial $\mathrm{R}$ indica el reanálisis que se produce en cada caso:

(1) esl. ant. blodb $\rightarrow$ blod-bnb $\rightarrow$ blod-bn-ikb$\quad$ (R: blod-(b)nikb)
'pecado' 'pecaminoso' 'pecador'
cf. oza $\rightarrow$ oz-bnikb
'celda'

blod-bn-ikb es reanalizado como blod-bnikb, tal como demuestra la derivación $o z a \rightarrow o z-b n i k b$

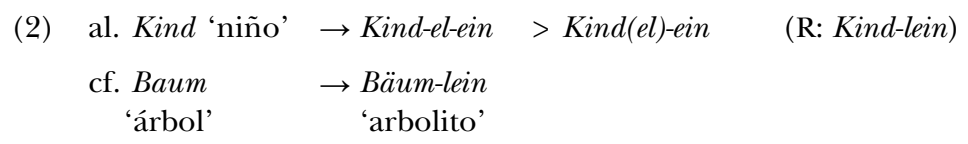

Kind(e)l-ein es reanalizado como Kind-lein, tal como demuestra la derivación Baum $\rightarrow$ Bäum-lein.

El desarrollo eslavo es especialmente revelador: la cadena derivativa que lleva de un sustantivo (blodb 'pecado') a otro (blod-bn-ikb 'pecador') pasando por el adjetivo denominativo (blod-bnb 'pecaminoso') pierde un eslabón y es así reducida a un solo paso ( $o z a$ 'celda' $\rightarrow o z-b n i k b$ 'prisionero') mediante la reinterpretación de una secuencia sufijal como un sufijo único. En la afijación de carácter telescópico se ha querido ver el efecto de la analogía proporcional, que extiende el sufijo unificado a nuevos contextos. Pero no es tan claro que el propio reanálisis, es decir, la resegmentación que conduce a la fusión de afijos, sea consecuencia de ese fenómeno analógico.

\subsubsection{Conglutinación}

El proceso de conglutinación, fenómeno levemente distinto al subtipo anterior (cf. $\S 4.1 .1$ ), puede ser ilustrado por las derivaciones ogoródnik 'jardín' $\rightarrow$ ogoródničestvo 'jardinería' del ruso y bijoutier 'joyero’ $\rightarrow$ bijouterie ‘joyería’ del francés (Haspelmath 1995, pp. 6-7):

(3) rus. ogoród-nik $\rightarrow$ ogoród-nič-estvo (R: ogoród-ničestvo)

Ogoród-nič-estvo es reanalizado como ogoród-ničestvo, tal como demuestra la derivación stoljár 'carpintero' $\rightarrow$ stoljár-ničestvo 'carpintería' (y no *stoljár-stvo)

(4) fr. bijout-ier $\rightarrow$ bijout-(i)er-ie $\quad$ (R: bijout-erie)

bijout-er-ie es reanalizado como bijout-erie, tal como demuestra la derivación orfềre $\rightarrow$ orfềr-erie (y no *orfềr-ie) 
A diferencia de la afijación telescópica, la conglutinación no puede ser reducida a un mero proceso de analogía proporcional (Haspelmath 1995 , p. 8), que daría como resultado formas no atestiguadas (*stoljár-stvo y *orfèr-ie) o bien significados que no se corresponden con los reales. Se trata más bien de un fenómeno de incremento afijal que puede estar directamente relacionado con los mecanismos léxicos de compensación por reducción fonológica (cf. § 8). En el terreno de la morfología la extensión de -erie a una base como orfềre sería paralela a innovaciones léxicas del tipo aujourd'hui 'hoy' (frente a *hui < lat. hodie).

Entre los ejemplos que Haspelmath incluye en la conglutinación hay alguno particularmente desafortunado que no responde fielmente a su propia definición de conglutinación. Es el caso de la derivación del pol. mieszczan(in) 'habitante, ciudadano' $\rightarrow$ mieszczan-ka, forma femenina reanalizada posteriormente como mieszcz-anka (como muestra la extensión a otras formas: kolega $\rightarrow$ koleż-anka). En el sustantivo polaco mieszczan(in), con un sufijo de origen singulativo -in que no tiene incidencia en la derivación, la secuencia -an-no puede ser considerada un sufijo (el autor, de hecho, no lo hace, al menos de manera explícita) que posteriormente queda integrado en -anka. Es, por tanto, más bien un hecho de secreción o de incorporación de un cuasi-afijo, tal como la entiende Haspelmath 1995, p. 11. La incoherencia de la interpretación de mieszczan-ka > mieszcz-anka como conglutinación resulta especialmente llamativa cuando se compara este caso con el reanálisis del antiguo indio $n \bar{a} m-a n-i$ 'nombres' $\rightarrow$ R: $n \bar{a} m$-ani $i$ (nuevo segmento extendido a formas de nom.-ac. pl. neut. como yug-ani 'yugos', perteneciente a la declinación temática), considerado por el mismo autor como ejemplo de incremento afijal por incorporación de un cuasi-afijo ${ }^{8}$.

\subsection{Secreción afijal}

En su concepción más restrictiva, el reanálisis morfológico que conduce a la secreción consiste esencialmente en la separación de segmentos constitutivos de un morfema, que pasan a formar parte de otro morfema generalmente gramatical. Esa separación acarrea de modo automático la modificación de las fronteras morfológicas de la palabra. En cuanto a los resultados, la secreción puede quedar limitada a un mero desplazamiento de la linde entre morfemas (con incremento afi-

\footnotetext{
${ }^{8}$ Para una interpretación del sufijo serbocroata -anin como combinación de dos (-an-in), propuesta pertinente en ese contexto y que contrasta con el análisis aquí expuesto del polaco, v. Rakič 2005. La presencia de alternancia de cantidad en la primera vocal del sufijo permite, al menos en teoría, la separación del sufijo serbocroata -anin en dos segmentos (esta circunstancia no se da en otros sistemas eslavos).
} 
jal como resultado recurrente, aunque también es posible la reducción afijal) o puede conllevar la creación de nuevas distinciones formales que se adecuan a las unidades de diferenciación semántica (lo que en otro lugar he llamado «secreción» en el sentido más restringido del término, cf. Igartua 2007-2008, pp. 30-32). Esta segunda manifestación de la secreción morfológica puede ser denominada emancipación morfosemántica. En la clasificación de Haspelmath, la secreción se refiere solo al primero de los dos resultados que cabe distinguir (con la limitación, además, de que el desplazamiento de la frontera morfológica ha de afectar únicamente a la relación entre raíz y sufijo).

\subsubsection{Incremento afijal}

Los ejemplos clásicos que ilustraron el fenómeno de la secreción (o, con otro término también añejo, el de la absorción) estaban vinculados en su mayor parte a resultados de extensión o incremento afijal. La raíz o el tema léxico de la palabra se desprende de alguno de sus elementos constitutivos, que pasan a formar parte del sufijo, derivativo o flexivo. Mencionaré varios ejemplos de esta clase de secreción, partiendo del primero que examinó Appel 1881; para algunos otros v. Haspelmath 1995, pp. 9-10:

(5) al. Menschen 'hombres' $\rightarrow$ R: Mensch-en (lo que era parte de la raíz o base léxica se convierte en sufijo desinencial).

(6) fr. fruit 'fruto' $\rightarrow$ fruit-ier 'frutero' $\rightarrow$ R: frui-tier, tal como demuestra su uso por ejemplo en bijoutier 'joyero', a partir de bijou 'joya'.

(7) fin. pyydys 'trampa' $\rightarrow$ pyydys-tää 'atrapar' $\rightarrow$ R: pyydy-stää, tal como demuestra la extensión del sufijo a kala 'pez' $\rightarrow$ kala-staa 'pescar'.

(8) rum. stea 'estrella', nom. sg. (< lat. stella), stel-e, nom. pl. (< lat. stell-ae), sufijo reanalizado como -le, tal como demuestran formas del tipo cafe-le 'cafés' (nom. sg. cafea) o perdele 'cortinas' (nom. sg. perdea).

(9) rus. slomít' 'romper', gerundio slom-já $\rightarrow$ R: slo-mjá, reflejado en la extensión del nuevo sufijo a formas actualmente adverbiales como rev-mjá 'a grito pelado' (de rev-é-t' 'gritar') o síd-mja 'sin moverse' (de sid-é-t' 'estar sentado').

La fuente del incremento afijal puede encontrarse en la sustancia fonológica de la raíz o base léxica, pero también en otros segmentos morfológicos más o menos reconocibles en el momento en el que se produce el reanálisis que conduce al incremento afijal. De hecho, el 
ejemplo más antiguo de secreción en los estudios de morfología diacrónica corresponde a la reinterpretación de un antiguo sufijo de formación nominal (-en en alto alemán antiguo) como nueva desinencia de plural. El resultado es, en cualquier caso, la ampliación del cuerpo fonológico de los nuevos afijos.

El caso del nuevo sufijo ruso de gerundio -mja es también un ejemplo de incremento afijal, pero presenta rasgos peculiares. Las formas en - mja se extienden a costa de las formas orgánicas en -ja, pero solo en el limitado conjunto de gerundios originarios que se convierten en adverbios ( revmjá, sídmja, živmjá, de ži(v)-ti 'vivir', cf. Vinogradov 1972, p. 293). $\mathrm{Al}$ mismo tiempo, el sufijo - ja sigue funcionando como marca de gerundio. Se produce por tanto una diferenciación secundaria de formas con arreglo al uso del sufijo originario (gerundios) o bien del conjunto resegmentado - mja (adverbios).

En la evolución de algunas lenguas romances, la segmentación originaria de formas latinas como temp-or-a (frente a temp-us) se volvió tempranamente opaca y el segmento intermedio pasó a engrosar el sufijo flexivo del nom. pl. de los sustantivos neutros (como en el caso del rumano) o de los masculinos inanimados (como en el dialecto italiano de la Puglia):

(10) rum. timp, nom. pl. timp-uri, con un sufijo -uri extendido posteriormente a nuevas formaciones del tipo hotel-uri 'hoteles'.

(11) it. Puglia. [óss-ərə] 'huesos', [ócc-ərə] 'ojos', [prát-ərə] 'prados' (Maiden 1997, p. 73) ${ }^{9}$

El incremento afijal puede provenir a su vez de la formación regresiva, relativamente frecuente en la relación entre formas del plural y del singular. Así, de latín corpus se obtuvo inicialmente esp. cuerpos, que fue posteriormente reinterpretado como cuerpo-s, con un singular de nueva formación cuerpo (lo mismo en inglés pease > peas 'pera', reanalizado como pea-s, y de ahí la oposición actual pea-peas).

$$
\text { formación regresiva: esp. cuerpos } \rightarrow \mathrm{R}: \text { cuerpo-s. }
$$

Pese a estos casos de raíz indudablemente analógica (el modelo de la oposición regular entre singular y plural está presente en el sistema antes del reanálisis), en el origen del incremento afijal no siempre se encuentra un proceso claramente discernible de analogía morfológica. La dirección de estas transformaciones (siempre hacia la ampliación de la sustancia fonológica de los afijos en detrimento de los demás com-

\footnotetext{
9 Agradezco a Alejo Alcaraz la referencia a estos reveladores ejemplos dialectales.
} 
ponentes de la palabra, algo que se observa en todos los ejemplos mencionados hasta ahora) resulta significativa y ello ha llevado a pensar en la integración de estas innovaciones morfológicas en un amplio proceso de renovación léxica y morfológica que, en el modelo de cambio lingüístico de Lüdtke 1986, constituye una respuesta a los mecanismos de reducción fonológica (v. infra §8). El problema es, como se verá posteriormente, que no todos los resultados del reanálisis morfológico apuntan en la misma dirección: los cambios que aquí englobaremos bajo los términos de reducción afijal y desafijación resultan ser precisamente inversos y ponen en entredicho cualquier proclamación de unidireccionalidad.

\subsubsection{Reducción afijal}

El resultado inverso al incremento afijal es el que cabe denominar reducción o retracción afijal, en cuyo marco es la raíz o el tema los que incorporan parte de los elementos constitutivos de un afijo, y no al revés. El mecanismo de separación morfológica que está en la base de toda secreción afijal conduce aquí al incremento de la sustancia del tema, hecho en general desatendido en anteriores clasificaciones (Haspelmath 1995) ${ }^{10}$.

(13) rus. $s n-j a t$ ' (rus. ant. sbn-ja-ti, cf. vbz-ja-ti 'tomar') $\rightarrow$ R: $s-n j a-t$ ' 'quitar', como demuestra la formación de otros verbos como pri-nját' 'recibir' o na-nját' 'contratar'.

En este ejemplo un segmento perteneciente en origen al afijo (prefijo rus. ant. $s b n-)$ es reanalizado como componente de la raíz, que de -ja- pasa a ser - nja- 'tomar'. Como se verá en $\S 8$ de este trabajo, la reducción del cuerpo fonológico del afijo resulta especialmente significativa desde una perspectiva teórica, puesto que, junto con el proceso de desafijación, constituye un contra-argumento de peso a la presunción de unidireccionalidad diacrónica en los fenómenos de reanálisis.

\footnotetext{
${ }^{10}$ En cambio, los casos de excreción o deglutinación (a nadder > an adder 'víbora', it. l'alicorno $>$ fr. med. la licorne 'el unicornio'), que consisten en la independización o trasvase de segmentos a un elemento funcional, sí suelen recogerse (Haspelmath 1995, p. 21; Koch 1996, p. 240). Los procesos de excreción dan lugar a separaciones léxicas, no propiamente afijales. El fenómeno inverso es el de la univerbación o aglutinación de segmentos independientes, fenómeno que se detecta en la sistemática incorporación del artículo árabe en los préstamos que el español tomó de aquella lengua (ár. hisp. al-qádi 'el alcalde' > esp. alcalde) o del artículo castellano en los sustantivos que el papiamento toma del español (laman 'mar' < esp. la mar), v. Detges 2003, pp. 53, 64 .
} 


\subsubsection{Emancipación afijal (o morfosemántica)}

Al tratar de la secreción, Jespersen 1922, § 19.13, incluyó en su exposición un curioso fenómeno dialectal del inglés. El sistema que describe dispone de los pronombres posesivos mine, thine, hisn y hern. Resulta llamativa la adición de $-n$ a los posesivos de tercera persona debido a que el segmento no corresponde a ningún corte formal ni semántico en el resto de la serie. Parece, por tanto, evidente, que en algún momento -n- en mine y thine fue reanalizado como marca de posesión, mientras el resto seguía estando asociado a la expresión de la persona. Se trata de la creación de un afijo y, por tanto, también de linde morfológica allí donde no había distinción alguna (v. también el comentario de Haspelmath 1995 , p. 25, n. 8).

En el origen de esta innovación, considerada extraña y tipológicamente rara, se encuentra la identidad y la recurrencia (al menos en dos pronombres de la serie) de un segmento despojado en principio de función, pero que resulta extendido a los demás miembros del paradigma mediante una probable analogía proporcional que tiene como resultado la nivelación paradigmática. Pudo tener incidencia en el proceso, dado que se trata de formas de gran frecuencia de uso, la llamada resonancia eidémica (eidemic resonance, v. Bickel y Nichols 2007, p. 209), proximidad formal que confiere mayor cohesión interna a series ya de por sí cerradas de formas. Esta perspectiva aportaría un dato diacrónico a favor de la influencia que puede llegar a tener la propia resonancia eidémica.

La emancipación formal y semántica -la conversión en afijo- de un elemento desprovisto de significado no es algo exclusivo, frente a lo que se ha podido pensar, de esta evolución dialectal inglesa. Es sin duda cierto que identificar esta clase de secreción es tarea ardua y no siempre al alcance, debido a la escasez de trabajos diacrónicos en multitud de lenguas. Pero en ocasiones un examen mínimamente detallado de algunas evoluciones puede conducir a la detección de casos similares de secreción derivados de lo que aquí llamo emancipación afijal o morfosemántica de determinados segmentos ${ }^{11}$. En concreto, y aunque la exposición detenida de los datos -para no sobrecargar este apartado de clasificaciónse ofrecerá en $\S 7$ del artículo, es elocuente el testimonio histórico de varios sistemas eslavos (principalmente orientales), cuya evolución flexiva conduce a la creación de una nueva linde morfológica. La comparación de formas actuales del paradigma plural con las que componían la declinación en ruso antiguo permite observar diferencias formales notorias:

\footnotetext{
${ }_{11}$ Andersen 2008, § 2.4.2.1 aplica el término morphosyntactic emancipation a los casos de desagregación morfológica que ilustran los ejemplos rusos idëm-te 'vamos', pólno-te 'ya basta', con el morfo -te (2⿺ pers. pl.) convertido en partícula enclítica (en lo que es un caso flagrante de desgramaticalización).
} 
(14) rus. dat. pl. gorod-ám 'a las ciudades' $\rightarrow$ R: gorod-á-m

\begin{tabular}{|c|c|c|c|c|}
\hline \multirow[b]{2}{*}{ Nom. } & \multicolumn{2}{|l|}{ rus. ant. } & \multicolumn{2}{|c|}{ rus. actual } \\
\hline & gorod-b & gorod $-i$ & górod & gorod-á \\
\hline Ac. & gorod-b & gorod-y & górod & gorod-á \\
\hline Gen. & gorod-a & gorod-b & górod-a & gorod-óv \\
\hline Dat. & gorod-u & gorod-omb & górod-u & gorod-ám \\
\hline Instr. & gorod-bmb & gorod-y & górod-om & gorod-ámi \\
\hline Loc. & 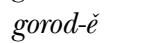 & gorod-ěxz & górod-e & gorod-áx \\
\hline
\end{tabular}

El paradigma plural de este y otros sustantivos (de todo género) puede en la actualidad ser analizado casi en su totalidad como raíz + formante de plural + marca de caso (por ejemplo, en el instr. pl. gorod-á-mi). La razón estriba en la identidad de la vocal $-a-$-dentro del paradigma y en buena parte de las clases flexivas- tanto en los casos oblicuos como en el nominativo. Solo el genitivo muestra una configuración distinta.

Una evolución similar ha experimentado el paradigma del numeral 'dos' en dialectos rusos y bielorrusos. A diferencia de la flexión estándar, que no distingue entre géneros más allá de los casos nominativo y acusativo, estos sistemas dialectales extienden la oposición de género (masculino-neutro frente a femenino) a todo el paradigma, como muestra la siguiente tabla (Andersen 1980, p. 25):

\begin{tabular}{|c|c|c|c|c|}
\hline \multirow[b]{2}{*}{ Nom. } & \multicolumn{2}{|c|}{ rus. estándar } & \multicolumn{2}{|c|}{ rus. dialectal } \\
\hline & $\begin{array}{l}\text { masc.-neut. } \\
d v a\end{array}$ & $\begin{array}{l}\text { fem. } \\
d v^{\prime} e\end{array}$ & $\begin{array}{l}\text { masc.-neut. } \\
d v a\end{array}$ & $\begin{array}{l}\text { fem. } \\
d v^{\prime} e\end{array}$ \\
\hline Ac. & \multicolumn{2}{|c|}{ =nom. $/$ gen } & \multicolumn{2}{|c|}{ =nom./gen. } \\
\hline Gen. & \multicolumn{2}{|c|}{$d v u x$} & $d v u x$ & $d v^{\prime} u x$ \\
\hline Dat. & \multicolumn{2}{|c|}{ dvum } & dvum & $d v^{\prime} u m$ \\
\hline Instr. & \multicolumn{2}{|c|}{ dvum'á } & dvum'á & dv'um'á \\
\hline Loc. & \multicolumn{2}{|c|}{$d v u x$} & $d v u x$ & $d v^{\prime} u x$ \\
\hline
\end{tabular}

La innovación de los casos oblicuos (palatalización generalizada en todo el paradigma) es la consecuencia formal del reanálisis emancipativo de uno de los elementos de significado gramatical, en concreto el género. En el sistema estándar la expresión del género no resulta segmentable, pero en la flexión dialectal el género femenino es asociado al carácter palatalizado del tema, de modo que, en la estela de Andersen 1980 , p. 25, podemos considerar que $d v^{\prime}-e$ fue reanalizado como $d v^{-}-e$ ('dos'-fem.-nom./ac.) y $d v$-ux como $d v$ - $\varnothing-u x$ ('dos'-fem.-gen./loc.). La materialización de los resultados del reanálisis responde a un proceso posterior de nivelación paradigmática o extensión analógica de la palatalización, que vienen a ser lo mismo (cf. § 1). 
(15) ruso y bielorruso dialectal: $d v^{\prime}-e$ 'dos (F.)' $\rightarrow \mathrm{R}: d v^{\prime}-e$ 'dos (F.)', como demuestra la extensión de la palatalización en el paradigma femenino: $d v^{\prime} u x, d v^{\prime} u m, d v^{\prime} u m^{\prime a ́ . ~}$

En el sufijo plural de formas neutras suecas como äpple-n 'manzanas' cabe entrever asimismo un proceso de emancipación morfosemántica. En su origen, el nominativo singular y el plural del paradigma indefinido no se distinguían entre sí: nom. sg. äpli, nom. pl. äpli. Las formas definidas se crean en plural mediante la adición del sufijo-(i)n. Pero en algunas variantes regionales del sueco del siglo XVII las formas definidas del neutro plural acababan en -na (en lugar de $-n$ ), probablemente por influjo de las formas determinadas masculinas y femeninas (fisk-ar-na 'los peces', gat-or-na 'las calles'). En sustantivos neutros de final en vocal, como äppli, la innovación produjo formas plurales definidas como äpple-na, que posteriormente fueron reanalizadas como äpplen-a. El paso siguiente llevó a la consideración de äpplen como nueva forma plural indefinida, estableciendo así una distinción formal entre el singular y el plural. Como resume Norde 2009, p. 65, "part of the suffix of definiteness was reanalysed as a plural suffix on the noun». De los ejemplos de emancipación morfosemántica, en este se percibe con mayor nitidez lo que podríamos llamar refuncionalización de un segmento afijal (perteneciente inicialmente al sufijo de determinación, pero emancipado posteriormente para indicar valor de plural). Este proceso de reciclaje funcional entra dentro del marco de la exaptación (Lass 1990), pero la exaptación no da entera cuenta del cambio producido en estos casos, puesto que además de una sustitución -aunque no completa- de función, aquí se observa una redistribución de la sustancia morfológica, parte de la cual sirve -una vez consolidada la innovación- para dar expresión a otro valor gramatical, el del número.

(16) sueco del siglo XVII: plural definido äpple-na, reanalizado como äpplen-a, como demuestra la creación de una nueva forma plural indefinida äpplen.

La emancipación es el caso por excelencia de la secreción. En el marco de este fenómeno una nueva distinción formal es segregada a partir o en el seno de una secuencia morfológica anteriormente indivisible.

\subsection{Desafijación}

El tercero de los fenómenos de reanálisis morfológico consiste en la disolución del componente afijal de la palabra en su base o parte léxica. Por sus rasgos, es un caso de reanálisis inverso al que representa el incremento afijal, aunque a diferencia de este, la desafijación afecta a todo 
el afijo en su conjunto, no solamente a uno de sus elementos constitutivos (como puede darse en el incremento). La desafijación se produce esencialmente como resultado de los procesos de creación de ceros morfológicos (Koch 1995, p. 33 ss., 39), aunque también presenta otras fuentes. Se pueden aducir ejemplos tanto nominales como verbales (el arrernte y el alyawarre son ambas lenguas arándicas del grupo pamanungano):

(17) provenzal (Clermont-Ferrand) $3^{\underline{a}}$ sg. del pasado del verbo 'cantar' canté-t $>$ cantét- $\varnothing$

\begin{tabular}{lll} 
& Paradigma I & Paradigma II \\
\hline $1^{\underline{\underline{a}}} \mathrm{sg}$. & cantée $-\dot{i}$ & cantét-e \\
$2^{\underline{\underline{a}}} \mathrm{sg}$. & canté-st & cantét-es \\
$3^{\underline{\underline{a}}} \mathrm{sg}$. & canté-t & cantét- $\varnothing$ \\
$1^{\underline{\underline{a}}} \mathrm{pl}$. & canté- $m$ & cantét-em \\
$2^{\underline{\underline{a}}} \mathrm{pl}$ & canté-tz & cantét-etz \\
$3^{\underline{\underline{a}}} \mathrm{pl}$. & canté-ren & cantét-on
\end{tabular}

(18) arrernte iwe-nhe 'qué-abs.' > iwenhe- $\varnothing$ alyawarre nhe-nhe 'este-abs.' > nhenhe- $\varnothing$

\begin{tabular}{lllll} 
& \multicolumn{2}{c}{ arrernte } & \multicolumn{2}{c}{ alyawarre } \\
\hline & Paradigma I & Paradigma II & Paradigma I & Paradigma II \\
\hline Abs. & iwe-nhe & iwenhe & nhe-nhe & nhenhe \\
Erg. & iwe-le & iwenhe-le & nhe-le & nhenhe-le \\
Dat. & iwe-ke & iwenhe-ke & nhe-ke & nhenhe-ke
\end{tabular}

La remodelación de paradigmas a partir de una forma determinada es producto del reanálisis morfológico de la forma de base ( $3^{\underline{a}}$ p. sg. en el caso de los verbos, caso absolutivo, nominativo o locativo en el caso de formas nominales, tema de plural en los sustantivos localmente no marcados en ese paradigma, cf. Tiersma 1982): lo que pertenecía al afijo pasa a ser considerado parte de la base a partir de la cual se recrea el paradigma entero. El reanálisis, por tanto, vuelve a generar un desplazamiento de la frontera morfológica, aunque en este caso la dirección del movimiento es inversa a la que puede detectarse en la mayor parte de los procesos de resegmentación. Las consecuencias teóricas de este tipo de reanálisis, al igual que ocurre con la reducción afijal, tienen, por eso mismo, una relevancia especial, como se tratará de subrayar en $\$ 8$.

Al margen de los procesos de creación de ceros morfológicos, la desafijación se detecta también en otros contextos. El caso del verbo ruso skazát' 'decir' es ilustrativo. Derivado por prefijación de una base kazát' > s-kazát' (cf. po-kazát' 'mostrar', kazát'sja 'parecer'), perdió posteriormente la posibilidad de esa distribución en morfemas, por lo que 
hoy día, y pese a la coincidencia de su segmento inicial con el prefijo $s$ ( $s$-délat' 'hacer', s-xodit' 'descender, pasarse por'), el morfema léxico, en realidad, no es otro que $s k a z-^{12}$ :

(19) rus. s-kaz-á-t', reanalizado como skaz-á-t' 'decir' (cf. la prefijación ulterior en pere-skazát' 'referir', ras-skazát' 'contar, relatar').

Desafijación es también la que se detecta en el proceso de reanálisis que conduce de la forma vasca de imperativo esaiozu 'dile', con base verbal esa-, doble marca de dativo de $3^{\underline{a}}$ p. sg. - $i-0$ - 'le' y sufijo agente $-z u$ 'tú', a una segmentación esai-o-zu que se encuentra en la base de las formas renovadas esaidazu 'dime', esaiguzu 'dinos' frente a las originarias esadazu, esaguzu, sin la marca adicional (de dativo de $3^{\underline{a}}$ p.). Parece razonable pensar aquí en una nivelación paradigmática a partir de esaiozu 'dile', esaiezu 'diles', cuyo resultado es la reinterpretación de - $i$ - como elemento flexivamente no distintivo, perteneciente, por tanto, a la base verbal.

(20) vasc. esa-i-o-zu, reanalizado como esai-o-zu, como demuestran las formas esai-da-zu, esai-gu-zu (en lugar de esa-da-zu о esa-gu-zu).

Al igual que los sufijos y los prefijos, también otros afijos pueden perder su valor gramatical para convertirse en segmentos no separables del morfema léxico. El infijo nasal para la formación del tema de presente en latín pierde, por ejemplo, ese valor $-\mathrm{y}$ por tanto su consideración como morfema- en el paso del latín al español. Frente a la oposición latina entre $v i<n>c-o$ y vic- $\bar{l}$, la lengua española (y también otras romances) presenta la extensión del tema de presente a todo el conjunto verbal (cf. venzo y vencí), con pérdida de la segmentación morfológica primitiva.

\subsection{Reafijación}

El último de los tipos formales de reanálisis que cabe observar puede ser denominado reafijación. La reafijación es entendida aquí como la reinterpretación formal de un afijo o procedimiento morfológico, sin que a consecuencia de esa reinterpretación varíen las fronteras morfológicas de la palabra ni se produzca una reasignación funcional del afijo o procedimiento en cuestión (algo que estaría más próximo a la exaptación como la entiende R. Lass). Se trata, por tanto, del único tipo de

\footnotetext{
${ }^{12}$ Salvo que se considere que en casos como este sigue siendo segmentable una raíz kazque tiene la particularidad de no poder aparecer -excepto en el verbo con sufijo reflexivo kazát'sja- si no es acompañado por un prefijo. Otra alternativa es entender el segmento $s$ - de skaz como submorfo, de la misma forma en que la secuencia -ec en oguréc 'pepino' es contemplada como submorfo con respecto a novgoródec 'habitante de Nóvgorod'. El caso de skazát' es en cierto modo similar al ingl. forgive 'perdonar', forget 'olvidar', donde no todos los especialistas están dispuestos a segmentar un elemento for- (Koch 1996, p. 241).
} 
reanálisis morfológico que no comporta directamente resegmentación, aunque sí está vinculado, según veremos, a la creación de una nueva linde morfológica. Su carácter formal -y no funcional- está libre de toda sospecha puesto que constituye un mecanismo de reconversión afijal, como ilustra el caso de reanálisis con reafijación más claro, el que proporcionan los datos del sánscrito (Joseph 1992, § 3.5):

(21) reduplicación como mecanismo de formación del perfecto en ind. ant.

$$
\begin{aligned}
& \text { pat- 'volar' > pa-pat- } \\
& \text { sth } \bar{a} \text { - 'estar' > ta-sthā- } \\
& \text { añ- 'moverse' > ān-añ- } \\
& \text { añc- 'doblar' > ān-añc- }
\end{aligned}
$$

El patrón con vocal inicial más nasal ( $\bar{a} n-a \tilde{n} g-, \bar{a} n$-añc-) es reanalizado como sufijo no reduplicativo de perfecto, como demuestra su extensión a

$$
\begin{aligned}
& r d h \text { - 'crecer' > ān-rodh- } \\
& \text { arh- 'merecer' > ān-roh- } \\
& \text { akș- 'alcanzar' > ān-akṣ- }
\end{aligned}
$$

En estas tres últimas formas no hay reduplicación, por lo que cabe pensar que el mecanismo regular de formación del perfecto ha sido previamente reanalizado como afijo no reduplicativo (un simple prefijo) con idéntica función: la de marcar el perfecto. El tipo de reanálisis que ilustra este caso acarrea, en opinión de Joseph 1992, p. 139, una mayor opacidad morfológica para el sistema («speakers lost sight of a seemingly obvious analysis and restructured in the direction of greater opacity»): frente a relaciones relativamente transparentes como las que se establecen en $a m s-$ 'alcanzar' y $\bar{a} n$-amos- por medio de la reduplicación. Sin embargo, hay margen suficiente en los datos para pensar que el reanálisis parte también en este caso de una situación previa de cierta opacidad (por no volver a introducir aquí la noción de ambigüedad, tal vez menos apropiada en este contexto): frente a reduplicaciones como $\mathrm{C}_{1} \mathrm{~V}_{1}-\mathrm{C}_{1} \mathrm{~V}_{1} \mathrm{C}_{2}$ (pa-pat-) o $\mathrm{C}_{2} \mathrm{~V}_{1}-\mathrm{C}_{1} \mathrm{C}_{2} \mathrm{C}_{3} \mathrm{~V}_{1}$ (ta-sth $\bar{a}$-, aunque con diferencias prosódicas en el vocalismo), en el caso de las raíces verbales con vocal inicial más sonante nasal ( $a m s-$-, $a \tilde{n} g$-), el resultado del proceso de reduplicación conduce a formas con vocal inicial larga (pese a la vocal breve de la raíz) ${ }^{13}$ y nasal alveolar (no necesariamente idéntica a la nasal radical). El concurso de ambas diferencias pudo ser razonablemente suficiente para que una generación de hablantes de sánscrito disociara la parte afijal de la radical hasta tal punto que la primera pasó

\footnotetext{
${ }^{13}$ Aquí tal vez el peso de la diferencia no depende tanto de la oposición de cantidad en sí, sino del hecho de que la relación entre vocal larga y vocal breve sea posicionalmente inversa a la que presenta el resto de verbos.
} 
a ser considerada un prefijo sin relación formal alguna con la configuración fonológica de la raíz verbal.

\section{PosibILIDADES DE RESEGMENTACIÓN Y TIPOS DE REANÁLISIS}

La operación de la resegmentación presenta tres opciones, como se ha indicado anteriormente. Las fronteras entre los morfemas pueden ser suprimidas, pueden ser creadas o pueden resultar desplazadas a lo largo de la evolución de los sistemas lingüísticos. El desplazamiento entraña, como sugiere Koch 1996, p. 239, una doble operación simultánea (o la combinación de las otras dos): la supresión de linde en un punto de la palabra y la creación de linde en otro.

La tipología del reanálisis morfológico recién expuesta distingue, por otro lado, más de tres clases e incluso dentro de alguna de ellas se establecen subtipos de reanálisis. Pero la división tripartita de las posibilidades de resegmentación en el marco de la palabra y los diversos tipos de reanálisis morfológico pueden ser interrelacionados en una visión integradora de ambas clasificaciones:

\begin{tabular}{|l|l|}
\hline \multicolumn{1}{|c|}{ Resegmentación } & \multicolumn{1}{c|}{ (Sub)clases de reanálisis } \\
\hline \multirow{2}{*}{ Supresión de linde morfológica } & Afijación telescópica \\
\cline { 2 - 2 } & Conglutinación \\
\cline { 2 - 2 } & Desafijación \\
\hline \multirow{2}{*}{ Creación de linde morfológica } & Emancipación afijal \\
\cline { 2 - 2 } & Reafijación \\
\hline \multirow{2}{*}{ Desplazamiento de linde morfológica } & Incremento afijal \\
\cline { 2 - 2 } & Reducción afijal \\
\hline
\end{tabular}

En cada tipo o subtipo de reanálisis hallamos, de esta manera, una de las operaciones básicas de resegmentación. La relación entre el incremento o la reducción afijal y el desplazamiento de linde morfológica es obvia, del mismo modo en que resulta evidente el vínculo entre la emancipación afijal y la creación de linde morfológica o el que existe entre desafijación y supresión de linde. En el caso de los dos fenómenos observados de fusión afijal (afijación telescópica y conglutinación), el proceso de supresión es también claro, aunque haya sido contemplado como desplazamiento (Haspelmath 1995, p. 4): si se produce el desplazamiento de frontera morfológica en esos dos casos que parten de una afijación doble es, en realidad, porque una linde ha sido eliminada. Por 
último, lo que aquí he denominado reafijación, tal vez el fenómeno de reanálisis más difícil de clasificar, puede asociarse a la creación de linde morfológica toda vez que, como en el ejemplo anteriormente examinado, un procedimiento morfológico como el de la reduplicación, sin base estable desde el punto de vista de la sustancia fonológica, acaba siendo reinterpretado como un afijo (con sustancia fonológica estable, es decir, no sujeta a variaciones dependientes de la configuración fonológica de la raíz).

En consecuencia, todas las clases y subclases de reanálisis morfológico se hallan englobadas en las tres posibilidades de resegmentación que pueden identificarse desde un punto de vista teórico.

\section{SOBRE LOS ORÍGENES DE LA SECRECIÓN (I): INCREMENTO Y REDUCCIÓN AFIJAL}

Tanto en el incremento como en la reducción afijal la resegmentación que da lugar a resultados opuestos parece depender en primera instancia del modelo morfológico que el reanálisis extiende (allí donde resulta aplicable una explicación por analogía). La reinterpretación estructural de cuerpos como cuerpo-s o la de sn-jat' como s-njat' es operativamente idéntica: en un caso, el modelo que extiende el proceso analógico es la relación regular entre las formas de singular y de plural, mientras que en el otro es la productividad del prefijo $s$ - (y no de $s n$-) el rasgo que favorece el reanálisis con resultado inverso desde el punto de vista de las relaciones entre tema y afijos.

No todos los casos de incremento afijal pueden ser inmediatamente explicados, sin embargo, mediante el recurso a la analogía. De hecho, buena parte de los ejemplos recogidos en el subapartado correspondiente se pliegan mal o no se pliegan en absoluto a la explicación por analogía. En estos casos, las formas que presentan los nuevos segmentos (cf. rum. cafe-le 'cafés', fin. kala-staa 'pescar') son entendidas como efectos de la propia redelimitación morfológica, no como modelos que anteceden al reanálisis producido en rum. ste-le o en fin. pyydy-staa, algo que resulta lógicamente imposible (-le no puede ser añadido a cafe para formar el plural si anteriormente no se ha llevado a cabo la resegmentación en stel-e) $)^{14}$.

${ }^{14}$ Aunque la argumentación sirve con carácter general para estos procesos de reanálisis, en el caso del rumano la nueva segmentación -le pudo estar influida por varios modelos preexistentes: uno es el nom. pl. de la declinación definida (-le) y, otro, la relación entre sg. y pl. de los préstamos procedentes del turco, conjunto léxico al que afecta fundamentalmente esta innovación (cf. tur. perde 'cortina' - perde-ler 'cortinas' con rum. perd-ea-perde-le, v. Schulte 2008, p. 335). La analogía, por tanto, no puede ser automáticamente descartada en esta resegmentación del rumano. 
En los procesos en los que no cabe el recurso a la analogía como fuente del reanálisis, el origen de la resegmentación se ha asociado a una tendencia universal a la compensación material de los efectos de la reducción fonológica, tendencia en la que se basa en buena medida el marco teórico sobre el cambio lingüístico de Lüdtke 1980; 1986. La reducción fonológica que producen los cambios de índole fonética (v. también Bybee 2001, p. 78, aunque cf. Blevins 2004, pp. 292-293) son de alguna forma compensados en los sistemas lingüísticos a través de varios medios: uno es la renovación léxica mediante la lexicalización y el otro, según la propuesta de Haspelmath 1995, pp. 22-23, podría ser el propio crecimiento de los afijos como tendencia universal de cambio que también está vinculada a la compensación material por la reducción fonológica, reducción que tiende a ser más acusada en los elementos de relevancia gramatical. La noción del crecimiento afijal como universal diacrónico será examinada en $\S 8$, por lo que aquí me limitaré a señalar que esa tendencia al aumento de la sustancia afijal está restringida, de entrada, por la acción de la analogía en los procesos de reanálisis morfológico, que puede conducir al incremento tanto del afijo como del tema léxico.

\section{SOBRE LOS ORÍGENES DE LA SECRECIÓN (II): EMANCIPACIÓN AFIJAL}

El que considero uno de los casos mejor acreditados de emancipación morfosemántica, i.e. la conversión de la flexión nominal de las lenguas eslavas orientales, en particular del ruso, en una estructura semiaglutinativa, con morfemas separados para la expresión del caso y del número, proporciona una visión particularmente clara del cúmulo de factores que pueden influir en un proceso de reanálisis morfológico. A continuación recojo un resumen de la secuencia evolutiva que conduce a la emancipación afijal en ruso y otras lenguas eslavas.

En fase de desarrollo medieval (a partir de los siglos XIII-XIV) comenzó a gestarse en eslavo nororiental (y, con menor repercusión, también en otras áreas dialectales) un proceso de innovación morfológica de consecuencias tipológicamente relevantes para la estructura de estas lenguas. La alteración principal está relacionada con la llamada desmorfologización del género en el paradigma plural de los sustantivos, es decir, con la supresión de las diferencias flexivas asociadas a la expresión del género en el plural ${ }^{15}$. El cambio afectó a los casos oblicuos: si en

\footnotetext{
${ }_{15}$ Mientras que en el paradigma singular la expresión de las distinciones de género seguía siendo activa. De acuerdo con el universal morfológico n. ${ }^{\circ} 37$ de Greenberg 1990 (1963), p. 58, «[a] language never has more gender categories in nonsingular numbers than in the singular». La desmorfologización del género en el plural lleva en varias lenguas eslavas a un sistema nominal asimétrico que se halla en consonancia con este principio tipológico.
} 
un principio cada clase flexiva contaba con sus formas específicas de dat., instr. y loc. pl., derivadas de la combinación particular del sufijo en su día temático con la desinencia propiamente dicha, en época tardomedieval todas esas diferencias formales fueron suprimidas a favor de un modelo unificado de flexión para esos casos. En la mayor parte de los sistemas flexivos eslavos son las antiguas formas en *-amb, *ami, *-axb las que tienden a generalizarse como marcas de los casos dat., instr. y loc. pl., respectivamente, con entera independencia de las diferencias de clase flexiva y género.

(22) evolución de los casos dat., instr. y loc. pl. en eslavo (esl. com. * gordb 'ciudad', *žena 'mujer', *město 'lugar').

\begin{tabular}{|c|c|c|c|}
\hline & \multicolumn{3}{|c|}{ situación del eslavo común } \\
\hline & masc. (tema en $-o$ ) & fem. $($ tema en $-\bar{a})$ & neutro (tema en $-o$ ) \\
\hline dat. & *gord-omb & *žen-amb & *měst-omъ \\
\hline instr. & *gord-y & *žen-ami & *měst-y \\
\hline loc. & *gord-е̌xъ & *žen-axz & ${ }^{*} m e \check{s t}-\check{e} x ъ$ \\
\hline
\end{tabular}

\begin{tabular}{|c|c|c|c|c|c|c|c|c|c|}
\hline & \multicolumn{3}{|c|}{ ruso } & \multicolumn{3}{|c|}{ polaco } & \multicolumn{3}{|c|}{ sorabo (alto) } \\
\hline & masc. & fem. & neutr. & masc. & fem. & neutr. & masc. & fem. & neutr. \\
\hline dat. & gorod-ám & žën-am & mest-ám & grod-om & żon-om & miast-om & hrod-am & žon-am & měst-am \\
\hline instr. & gorod-ámi & žën-ami & mest-ámi & grod-ami & $\dot{z}$ on-ami & miast-ami & hrod-ami & žon-ami & měst-ami \\
\hline loc. & gorod-áx & žën-ax & mest-áx & grod-ach & $\dot{z}$ on-ach & miast-ach & hrod-ach & žon-ach & měst-ach \\
\hline
\end{tabular}

Si bien las formas resultantes en eslavo oriental y parte del occidental coinciden externamente con el aspecto que presentan en origen los temas en $-\bar{a}$ (mayoritariamente femeninos, cf. el modelo de žena) ${ }^{16}$, el motivo de su generalización parece hallarse más bien en la uniformidad o cohesión interna que caracterizaba los casos periféricos de estos te-

\footnotetext{
${ }^{16}$ Constituye una excepción al menos aparente el dat. pl. en -om del polaco (frente a -ami, -ach del instr. y del loc. pl.). Según la opinión más extendida entre los especialistas, el origen de la terminación común de dat. pl. en polaco se encuentra en la confluencia de -am (o más bien -ám/-åm, puesto que la vocal desinencial era larga) y de -om en una sola pronunciación cerrada [-om] que explicaría de modo fonético la singularidad de esta desinencia entre las terminaciones unificadas del plural.
} 
mas en contraste con la dispersión formal de otros (entre ellos los antiguos temas en $-o$, representados en el cuadro): cf. -amb, -ami, -axb

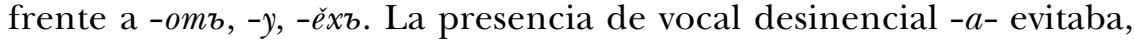
además, las alternancias consonánticas a que daba lugar, entre otras, la vocal $-\check{e}$-, que tras consonante velar generaba una palatalización con mutación del tipo *vblk-ěxb 'lobos' > *vblc-ěxb (esl. ant. vlbcěxb frente a dat. pl. vlbkomb o instr. pl. vlbky). Desde el punto de vista de la transparencia morfotáctica, resultaban preferibles, por tanto, las terminaciones con - $a$ - como vocal desinencial.

En el contexto de la desmorfologización del género en plural, la unidad formal se convierte, como formuló Andersen 1969, p. 27, en la expresión óptima de la ausencia de diferencias semánticas. La supresión de las antiguas oposiciones formales asociadas a la expresión del género, inmediatamente traducida en la unificación del paradigma plural (al menos en los casos oblicuos) de casi todos los sustantivos, estuvo precedida por el proceso de uniformación que afectó a la declinación plural de los adjetivos determinados y los pronombres. En ambos casos, los motivos de la equiparación formal de todos los géneros son en parte fonéticos, en parte morfológicos. En los adjetivos determinados la adición de la marca $* j b,{ }^{*} j a,{ }^{*} j e$, procedente del pronombre relativo indoeuropeo, a la forma estrictamente nominal conducía a las mismas distinciones de género ya presentes en las formas breves. Solo la extensión secundaria de la vocal $-y$-, desarrollada fonéticamente en casos como el gen. pl. de todos los géneros o en el instr. pl. no femenino y conservada en el ac. pl. masc. y neutro, pudo causar la neutralización de las diferencias de género en plural, que para el común de las lenguas eslavas es un fenómeno antiguo en los casos oblicuos y, por el contrario, relativamente moderno en los casos rectos y limitado, además, al área oriental. A consecuencia del proceso de unificación formal, dentro de la flexión de los pronombres y adjetivos se pueden identificar en las vocales $-\check{e}-(>-e-)$, por un lado, $-y-/-i-$, por otro, sendas marcas pluralizadoras, no vinculadas directamente a la expresión del caso.

(23) esl. com. *noøbjb 'nuevo' ruso nóvyj 'nuevo'

\begin{tabular}{|c|c|c|c|c|}
\hline & \multicolumn{3}{|c|}{ pl. } & \multirow{2}{*}{$\frac{\text { pl. }}{\text { masc.-neutro-fem }}$} \\
\hline & masc. & neutro & fem. & \\
\hline nom. & ${ }^{*} n o v b-j b$ & *nova-ja & *novy-je & nóv-ye \\
\hline ac. & *novy-je & *nova-ja & *novy-je & nóv-ye \\
\hline gen. & \multirow{4}{*}{\multicolumn{2}{|c|}{$\begin{array}{l}{ }^{*} \text { novb-jixъ } \\
{ }^{*} \text { novomz-jims } \\
\text { *novy-jimi } \\
\text { *novéxъ- } i i x z\end{array}$}} & *novb-jixz & nóv-yx \\
\hline dat. & & & ${ }^{*}$ novamb-jams & nóv-ym \\
\hline instr. & & & *novami-jami & nóv-ymi \\
\hline loc. & & & *novaxb-jaxz & nóv-yx \\
\hline
\end{tabular}


La eliminación de las distinciones de género en nom. y ac. pl., unida a la homonimización de estos casos, lleva al desarrollo de un nuevo paradigma unificado, donde morfológicamente cabe segmentar formas como rus. nóvymi en nóv-y-mi o nóvyx en nóv-y-x. Entre los sustantivos, la unificación -iniciada en buena parte del eslavo- se alcanzó en los casos dativo, instrumental y locativo, mientras que en genitivo y en los casos rectos perduran en general las diferencias, tanto en lo que concierne a la expresión del género (en nom.-ac. pl.: formas en - a para el neutro, en $-y$ para el femenino y masculino, en $-i$-con excepciones fonéticas- e incluso las que proceden de *-ove para el masculino). No obstante, conviene recordar a este respecto la tendencia que se observa fundamentalmente en eslavo oriental (ruso) y solo parcialmente en el occidental (polaco y checo) al desarrollo de formas rectas en - $a$ entre los sustantivos masculinos (y en algunas variedades dialectales incluso entre los femeninos: rus. gorodá 'ciudades', rus. dial. cerkvjá 'iglesias'). A excepción, por tanto, del gen. pl., que conserva sus desinencias orgánicas, por más que no siempre sirvan para distinguir entre géneros, el paradigma plural de los sustantivos presenta en eslavo oriental (sobre todo en ruso) un aspecto profundamente unificado, tanto en lo que se refiere a la desmorfologización del género como en lo que atañe a la cohesión puramente formal, interna, del paradigma. En estas nuevas circunstancias flexivas resulta posible el reanálisis morfológico que conduce a la secreción de un nuevo formante de plural mediante la creación de una frontera morfológica antes inexistente:

(24) rus. górod 'ciudad'

\begin{tabular}{|c|c|c|}
\hline & antes del reanálisis & tras el reanálisis \\
\hline & pl. & pl. \\
\hline nom. & gorod-á & gorod-á-Ø \\
\hline ac. & gorod-á & gorod-á-Ø \\
\hline gen. & gorod-óv & gorod-óv \\
\hline dat. & gorod-ám & gorod-á-m \\
\hline instr. & gorod-ámi & gorod-á-mi \\
\hline loc. & gorod-áx & gorod-á-x \\
\hline
\end{tabular}

En ruso actual se produce, como indicó ya Zaliznjak 2002 (1967), p. 549, la disociación flexiva de número y caso (gorod-á-m, gorod-á-mi, gorod-á-x). Los únicos rasgos que aún mantendrían la flexión nominal rusa algo alejada de una estructura enteramente aglutinativa son, por un lado, el carácter fusionante del gen. pl. (morfo -ov) y, por otro, la dis- 
crepancia entre las marcas de caso en singular y en plural: cf. dat. sg. górod-u vs. dat. pl. gorod-á-m, instr. sg. górod-om vs. instr. pl. gorod-á-mi, loc. sg. górod-e vs. loc. pl. gorod-á-x. Y, pese a ello, el análisis morfológico que corresponde hoy día a la relación entre nom. sg. y nom. pl. (cf. górod- $\varnothing$ vs. gorod-á- $\varnothing$ ) revela un isomorfismo flexivo que puede calificarse de canónico para un sistema aglutinante.

A lo largo de este proceso de modificaciones morfológicas, se registran, por tanto, los siguientes hechos:

1. Unificación formal del paradigma plural.

2. Expansión del morfo -á de nom. pl. masc.

3. Expansión (limitada) del morfo -á de nom. pl. en fem.

4. Presencia del modelo adjetival (-y-) y pronominal $\left(-i / e^{-}\right)$.

El conjunto de estos hechos diacrónicos permite la reinterpretación estructural, en este caso la separación de los formantes de número y caso. El resultado proviene, por tanto, de la acumulación accidental de varios elementos. La secreción halla su punto de partida en la unificación formal del plural (causa material), pero se apoya en buena medida en el modelo paradigmático de los adjetivos y de los pronombres (causa formal). Este segundo aspecto del reanálisis lo vincula a la analogía como fuente tal vez necesaria, aunque no suficiente, para la emancipación de los formantes de número y caso.

La inserción de una linde morfológica -o, lo que es lo mismo, la conversión de un segmento anteriormente indiviso en un afijo- como la que separa el morfo de plural del morfo de caso en la declinación del sustantivo en ruso encuentra también paralelos en el ámbito del préstamo lingüístico. Un ejemplo particularmente claro es el del holandés zonnedek, tomado en préstamo por la lengua rusa como zóntik 'paraguas' e inmediatamente reanalizado como formación diminutiva zónt-ik, según el modelo de dóm-ik 'casita' o stól-ik 'mesilla' (y de ahí la forma regresiva zont 'paraguas'). Un proceso de adaptación morfológica similar es el que ilustra el conocido ejemplo del swahili kitabu 'libro' (préstamo del árabe kitabu) $\rightarrow$ R: ki-tabu 'CL-libro', con ki-como marca de clase nominal, como demuestra la forma de plural vi-tabu 'CL-libros', cf. kikombe 'copa' - vikombe 'copas' (Anttila 2003, p. 427; Itkonen 2005, p. 9). También en este caso un segmento perteneciente al tema léxico de la palabra es reanalizado, debido a la coincidencia material con un segmento morfológicamente relevante de la lengua, como afijo. En los casos de secreción en préstamos léxicos la preexistencia de modelos morfológicos -es decir, la acción de la extensión analógica- parece lejos de toda duda.

Los procesos de emancipación morfosemántica se pueden asociar a la codificación transparente de las relaciones entre significante y significado. Desde una perspectiva morfológica natural, la tendencia bastaría 
en principio para entender, tipológicamente hablando, este tipo de evolución. Desde una óptica evolutiva (que va de los datos a la explicación de las tendencias observables, no de las tendencias generales a la explicación de datos), esa tendencia es más bien el resultado de alteraciones morfológicas independientes (el caso de la - $a$ - como nuevo formante del plural es, en mi opinión, particularmente claro) que posibilitan el posterior reanálisis segmental. Los distintos cambios morfológicos sientan las bases de la ambigüedad interpretativa que es necesaria para el reanálisis: la recurrencia de la vocal - $a$ - (que presenta orígenes distintos) posibilita la nueva segmentación. Este proceso de secreción conduce a una estructuración muy próxima a la que resulta característica de los sistemas aglutinantes, equiparable a esta en lo que respecta a la condición puramente estructural (disociación de los formantes de número y caso), aunque distinta en lo que concierne a la condición formal (identidad de las marcas de caso en singular y en plural), cf. Igartua 2007-2008, p. 29. La resegmentación cumple, por otra parte, los requisitos tipológicos del orden de marcas: el morfema de número precede al morfema de caso, y no a la inversa (universal n. ${ }^{\circ} 39$ de Greenberg).

\section{EL CRECIMIENTO AFIJAL COMO UNIVERSAL DIACRÓNICO}

Una de las conclusiones de la investigación de Haspelmath 1995, p. 21 consiste en la defensa del crecimiento afijal -del aumento de la sustancia de los afijos- como universal de evolución morfológica. Los ejemplos y los tipos de reanálisis que recogió el autor así parecían indicarlo, pero la realidad es que hay otros casos de reanálisis morfológico que no avalan esa conclusión, al menos en su variante fuerte. La fusión (afijación telescópica y conglutinación) redunda en el crecimiento afijal, sin duda alguna; también lo hace el primer tipo de secreción, que desemboca precisamente en el incremento afijal; pero la reducción afijal y la desafijación son procesos inversos a la dirección evolutiva que Haspelmath consideraba única. La reafijación no es a este respecto relevante, pero los casos de emancipación afijal representan nuevamente, como detallaré abajo, un tipo de evolución inverso al aumento de la sustancia fonológica de los afijos.

Parece, en consecuencia, claro que no puede sostenerse con carácter general la idea de unidireccionalidad en los procesos de reanálisis morfológico. Por otro lado, y aunque no disponemos de datos de frecuencia, sí resulta probable, no obstante, el hecho de que los casos (no tanto los tipos) de crecimiento afijal sean superiores en número a los casos de reducción afijal. Esta tendencia, no exenta de excepciones que distan de ser aisladas, encuentra un encaje idóneo, como sugiere Haspelmath, en el marco teórico desarrollado por Lüdtke 1980; 1986, 
p. 23 ss. En la concepción de este último, el desgaste material producido por la reducción fonológica tiende a ser compensado en las lenguas mediante procedimientos vinculados a lo que él llama «amplificación» o «enriquecimiento semantáctico ${ }^{17}$. La pérdida de sustancia fonológica es contrarrestada, según esta visión, por medio de la renovación léxica a través de lexicalizaciones (fr. aujourd'hui 'hoy' en lugar de *hui < lat. hodie, ing. world 'mundo' < *wer-ald- 'edad del hombre'), de alargamientos derivativos (esp. oreja < lat. auricula, cf. auris), o bien, como añade Haspelmath 1995, pp. 22-23, al esquema de Lüdtke, a través de resegmentaciones morfológicas que conducen, allí donde resultan posibles $^{18}$, al crecimiento afijal. En este segundo caso, la compensación por la reducción fonológica está limitada a los segmentos con valor gramatical, que incrementan su sustancia fonológica en detrimento de la sustancia de los morfemas léxicos.

La observación está en consonancia con la tendencia morfológica V de Mańczak 1958, que puede ser formulada de esta manera: las terminaciones monosilábicas son reemplazadas por terminaciones polisilábicas con más frecuencia que al revés, como ilustran estos casos:

(25) checo dat. sg. chlap-u $\rightarrow$ chlap-ovi 'al chico'

vasc. adl. sg. Gasteiz- $a \rightarrow$ Gasteiz-era 'a Vitoria'

La tendencia proporciona pistas acerca de la lógica de la renovación formal en las lenguas naturales (y aquí cabe de nuevo la apelación a fenómenos compensatorios), pero, como en el resto de sus tendencias morfológicas, el autor polaco se refiere también aquí a correlaciones de frecuencia, no a posibilidades evolutivas únicas ${ }^{19}$.

Otro proceso que redunda en el enriquecimiento semantáctico es la remodelación de paradigmas involucrada en la creación de ceros morfológicos (o desafijación). El desarrollo de un cero morfológico es un proceso en principio reductivo (contrario, por tanto, a la tendencia a la que nos referimos), pero la consecuencia es el aumento de la sustancia fonológica de los temas nominales o verbales, al tiempo que, en general, los morfemas flexivos no pierden sustancia salvo en aquel valor que experimenta la reducción formal a morfo cero. De ahí que los ceros morfológicos no constituyan un fenómeno direccionalmente inverso al incremento afijal.

\footnotetext{
17 «Lüdtke's term 'semantactic' is intended to capture the fact that the renewed expression is not only formally richer, but also semantically» (Haspelmath 1995, p. 26, n. 20).

${ }^{18}$ Es decir, donde el hablante encuentra duplicidad interpretativa (ambigüedad estructural u opacidad) que puede ser resuelta en uno o en otro sentido (cf. el dictum de Plank 2004, p. 179: «Reanalysis is therapy, not prophylaxis»).

${ }^{19}$ Otro ejemplo pertinente en este contexto es su tendencia IV: las desinencias cero son reemplazadas por marcas plenas con mayor frecuencia que al revés, como en el caso de la evolución de ingl. ant. word: word al moderno word: words.
} 
Pero, según se adelantaba al comienzo de esta sección, además de la reducción y de la desafijación, resultados contrarios por definición a la idea de crecimiento afijal como universal diacrónico, también la emancipación afijal desemboca en la disminución de la sustancia fonológica de los afijos. El caso ilustrado por las formaciones dialectales inglesas hisn, hern no es a este respecto informativo (la creación del afijo consiste en la emancipación de la nasal radical en mine, thine), pero tanto los ejemplos eslavos como el sueco apuntan en un sentido inequívoco: la emancipación afijal o morfosemántica entraña resegmentación con resultado de reducción de la sustancia fonológica de los morfemas, en su caso de los afijos. Es cierto que la evolución rusa (consistente en la creación de una distinción morfémica nueva) supone el aumento del número de afijos, pero a cambio, dado que no se produce adición alguna, el afijo único que existía anteriormente para la expresión de las categorías de número y caso ve inevitablemente reducido su cuerpo fonológico.

Desde la perspectiva de una tipología del reanálisis morfológico no puede defenderse el carácter supuestamente universal del crecimiento de los afijos a consecuencia de los procesos de reanálisis. A juzgar por los resultados constatados, el reanálisis no va encaminado en una dirección única, los hablantes no llevan a cabo resegmentaciones morfológicas cuyo desenlace sea exclusivamente el aumento de la sustancia afijal en detrimento de la de los morfemas léxicos. Cada resultado depende de los factores que actúan en el proceso de reanálisis (especialmente claros cuando entre ellos se encuentra -y lo hace asiduamente- la analogía), y esos factores pueden sin duda alguna variar, por más que la mayor frecuencia, si se confirma, de los casos de crecimiento afijal pueda estar en relación con una tendencia general a la renovación de segmentos breves por segmentos más largos. Esa tendencia, sin embargo, no impide resegmentaciones cuyo resultado es la reducción de la sustancia fonológica de los afijos.

\section{Conclusiones}

La clasificación de los tipos de reanálisis morfológico ofrecida en este trabajo revela la notable variedad de resultados que producen los fenómenos de resegmentación. La alteración de la distribución morfológica de una palabra depende, como punto de partida, de la opacidad o de la ambigüedad estructural. La opacidad surge cuando no hay razones para seguir vinculando el material fonológico a ambos lados de la frontera morfológica a unidades de significado distintas. Por su parte, una linde se vuelve ambigua cuando los hablantes disponen de más de una posibilidad de análisis morfológico de la palabra (Koch 1996, p. 237). Es 
difícil que ambas circunstancias puedan concurrir: si una linde morfológica se vuelve opaca, no parece que pueda darse una doble interpretación estructural (la antigua y una nueva) para esa secuencia (posible solo en el caso de que esta pudiera interpretarse de dos formas nuevas).

Esos dos factores, la opacidad y la ambigüedad, establecen la posibilidad del reanálisis, pero no exigen el reanálisis. Como en otros ámbitos del cambio lingüístico, también aquí resultan relativamente diáfanos los mecanismos y las motivaciones, pero no puede predecirse la actuación del reanálisis (cf. Itkonen 2005, p. 75: «No theory can predict linguistic changes», con subrayado del autor). En entornos tipológicamente similares, el reanálisis se produce en unos casos y no en otros. Lo que determina la investigación de los hechos de reanálisis morfológico, al igual que ocurre con la analogía, es el tipo de cambios que pueden producirse y las fuentes de esos cambios en el caso de que se active el proceso de modificación.

Al margen -pero también como resultado- de la propia clasificación del reanálisis, a lo largo de este estudio se han tratado de comprobar dos hipótesis fundamentales en torno a este proceso de modificación en la morfología. La primera de ellas guarda relación con el carácter supuestamente universal del crecimiento de los afijos mediante reanálisis. La segunda se plantea la autonomía del reanálisis como mecanismo de cambio morfológico. Los datos examinados en este trabajo ponen de manifiesto que:

1) El reanálisis morfológico no conduce necesariamente al crecimiento de los afijos; la resegmentación no es un fenómeno unidireccional, por más que presente cierta predisposición a una de las direcciones; se ha de ver en cada caso la incidencia de los modelos que influyen para que el reanálisis actúe en un sentido, el del aumento de la sustancia de los afijos, o en otro, en el de su reducción;

2) El reanálisis morfológico presenta un carácter relativamente autónomo en tanto mecanismo de cambio en morfología: aunque en muchos casos es dependiente de la analogía, o, por decirlo de otro modo, la analogía suele preceder a la acción del reanálisis (del reanálisis que podemos denominar «analógico», cf. Detges 2003, p. 57), este tiene, por un lado, componentes específicos (para el reanálisis es necesaria bien la opacidad morfotáctica, bien la ambigüedad estructural, para la analogía no) y, por otro, no siempre parte de una situación en la que pueda resultar aplicable la analogía: hay tanto modificaciones analógicas sin reanálisis (no toda extensión analógica produce como resultado un reanálisis) como, y esto es lo relevante, procesos de reanálisis sin aparente incidencia previa de la analogía. 
Finalmente, si el reanálisis fuera siempre y necesariamente a remolque de la analogía, es decir, si dependiera en toda ocasión de un modelo estructural preexistente, parece lógico pensar que el reanálisis, a diferencia de la propia analogía (Deutscher 2005, p. 208), no podría introducir novedades en la lengua (véase para ello Itkonen 2002, pp. 419-420), lo cual no es del todo cierto (cf., por ejemplo, el caso de las formas adverbiales rusas en -mja). Por otra parte, las diferencias entre analogía (como proceso de cambio) y reanálisis pueden vincularse a la actividad innovadora del hablante, en el primer caso, y a la del oyente, en el segundo (Marchello-Nizia 2006, pp. 46, 86-87), de tal forma que los condicionantes de un proceso y otro, debido a su origen diverso, no tienen por qué coincidir. De la manifestación material de esas diferencias se sigue la relativa autonomía que puede reconocérsele al reanálisis en tanto mecanismo de cambio morfológico.

\section{REFERENCIAS BIBLIOGRÁFICAS}

ANDERSEN, H. (1969): «The peripheral plural desinences in East Slavic», International Journal of Slavic Linguistics and Poetics 12, pp. 19-32.

- (1973): «Abductive and deductive change», Language 49, pp. 765-793.

- (1980): «Morphological change: towards a typology», en Fisiak, J. (ed.), Historical Morphology, La Haya-París-Nueva York, Mouton de Gruyter, pp. 1-50.

- (2008): «Grammaticalization in a speaker-oriented theory of change», en Eythórsson, Th. (ed.), Grammatical change and linguistic theory. The Rosendal papers, Ámsterdam-Filadelfia, pp. 11-44.

ANTTILA, R. (2003): «Analogy: The warp and woof of cognition», en Joseph, B. D. y Janda, R. D. (eds.), The handbook of historical linguistics, Londres, Blackwell, pp. 425-440.

APPEL, K. (1881): «Něskol'ko slovъ o novějšemъ psixologičeskomъ napravlenii jazykoznanija», Russkij filologičeskij věstnikъ 6, 3, pp. 93-142.

BAUdouin DE CourtenaY, J. (1963 = 1902): «Zametka ob izmenjaemosti osnov sklonenija, v osobennosti že ob ix sokraščenii v pol'zu okončanij», Izbrannye trudy po obščemu jazykoznaniju, v. II, Moscú, Akademija SSSR, pp. 19-29.

BECKER, Th. (1990): Analogie und morphologische Theorie, Munich, Fink.

Bickel, B. y NichOls, J. (2007): «Inflectional phonology», en Shopen, T. (ed.), Language typology and syntactic description. III. Grammatical categories and the lexicon, Cambridge, Cambridge University Press, pp. 169-240.

Blevins, J. (2004): Evolutionary phonology, Cambridge, Cambridge University Press.

BogorodickIJ, V. A. (1915): Lekcii po obščemu jazykovědeniju, Kazán, Izdatel'stvo kazanskogo universiteta.

BybeE, J. (2001): Phonology and language use, Cambridge, Cambridge University Press.

- (2006): «From usage to grammar: The mind's response to repetition», Language 82, pp. 711-733. 
CAMPBELL, L. (2001): «What's wrong with grammaticalization», Language Sciences 23, pp. 113-161.

Croft, W. (2000): Explaining language change: An evolutionary approach, Londres, Longman.

- (2006): "The relevance of an evolutionary model to historical linguistics», en Thomsen, O. N. (ed.), Different models of language change, ÁmsterdamFiladelfia, John Benjamins, pp. 91-132.

DE SMET, H. (2009): «Analysing reanalysis», Lingua 119, pp. 1728-1755.

Detges, U. (2003): «La notion de réanalyse et son application à la description des langues créoles», en Kriegel, S. (ed.), Grammaticalisation et réanalyse. Approaches de la variation créole et française, París, CNRS, pp. 49-68.

Deutscher, G. (2001): «On the mechanisms of morphological change», Folia Linguistica Historica 22, pp. 41-48.

- (2002): «On the misuse of the notion of 'abduction' in linguistics», Journal of Linguistics 38, 3, pp. 469-485.

- (2005): The unfolding of language, Nueva York, Metropolitan Books.

Elvira, J. (2009): Evolución lingüistica y cambio sintáctico, Frankfurt, Peter Lang.

Fischer, O. (2007): Morphosyntactic change. Formal and functional perspectives, Oxford, Oxford University Press.

- (2008): «On analogy as the motivation for grammaticalization», Studies in Language 32, 2, pp. 336-382.

Garrett, A. (2008): "Paradigmatic uniformity and markedness», en Good, J. (ed.), Explaining linguistic universals: Historical convergence and universal grammar, Oxford, Oxford University Press, pp. 125-143.

- (2012): «The historical syntax problem: Reanalysis and directionality», en Jonas, D., Whitman, J. y Garrett, A. (eds.), Grammatical change: Origins, nature, outcomes, Oxford, Oxford University Press, pp. 52-72.

GREENBERG, J. H. $(1990=1963)$ : «Some universals of grammar with particular reference to the order of meaningful elements», en Greenberg, J. H., On language. Selected writings (ed. por K. Denning y S. Kemmer), Stanford, Stanford University Press, pp. 40-70.

Harris, A. C. y CAMPBell, L. (1995): Historical syntax in a cross-linguistic perspective, Cambridge, Cambridge University Press.

Haspelmath, M. (1995): «The growth of affixes in morphological reanalysis», Yearbook of Morphology 1994, pp. 1-29.

- (1998): «Does grammaticalization need reanalysis?», Studies in Language 22, pp. 315-351.

Hopper, P. J. y Traugott, E. C. (2003): Grammaticalization, 2ae ed., Cambridge, Cambridge University Press.

IgARTUA, I. (2007-2008): «Ciclos invertidos. En torno a la direccionalidad del cambio tipológico», Die Sprache 47/1, pp. 1-47.

ITKOnEN, E. (2002): "Grammaticalization as an analogue of hypothetico-deductive thinking», en Wischer, I. y Diewald, G. (eds.), New reflections on grammaticalization, Ámsterdam-Filadelfia, John Benjamins, pp. 413-422.

- (2005): Analogy as structure and process, Ámsterdam-Filadelfia, John Benjamins. 
JESPERSEN, O. (1922): Language: Its nature, development and origin, Londres, Allen \& Unwin.

JoSEPH, B. D. (1992): «Diachronic explanation: Putting speakers back into the picture», en Davis, G. W. e Iverson, G. K. (eds.), Explanation in historical linguistics, Ámsterdam-Filadelfia, John Benjamins, pp. 123-144.

- y JANDA, R. D. (1988): «The 'how' and 'why' of diachronic morphologization and demorphologization», en Hammond, M. y Noonan, M. (eds.), Theoretical morphology. Approaches in modern linguistics, San Diego, Academic Press, pp. 193-210.

KIPARSKY, P. (2012): «Grammaticalization as optimization», en Jonas, D., Whitman, J. y Garrett, A. (eds.), Grammatical change: Origins, nature, outcomes, Oxford, Oxford University Press, pp. 15-51.

KRUŠEVSKIJ, N. V. $(1998$ = 1880): «O morfologičeskoj absorbcii», Izbrannye raboty po jazykoznaniju, Moscú, Nasledie, pp. 62-64.

KocH, H. (1995): «The creation of morphological zeroes», Yearbook of Morphology 1994, pp. 31-71.

- (1996): «Reconstruction in morphology», en Durie, M. y Ross, M. (eds.), The comparative method revisited. Regularity and irregularity in language change, Oxford, Oxford University Press, pp. 218-263.

LANGACKer, R. W. (1977): «Syntactic reanalysis», en Li, Ch. N. (ed.), Mechanisms of syntactic change, Austin-Londres, University of Texas, pp. 57-139.

LASS, R. (1990): «How to do things with junk: Exaptation in language evolution», Journal of Linguistics 26, pp. 79-102.

- (1997): Historical linguistics and language change, Cambridge, Cambridge University Press.

LINDSTRÖM, Th. Å. M. (2004): «Grammaticalisation and explanation vs coalescence and secretion», Beiträge zur Geschichte der Sprachwissenschaft 14, pp. 251-284.

LüDTKE, H. (1980): «Auf dem Wege zu einer Theorie des Sprachwandels», en Lüdtke, H. (ed.), Kommunikationstheoretische Grundlagen des Sprachwandels, Berlín, Mouton de Gruyter, pp. 182-252.

- (1986): «Esquisse d'une théorie du changement langagier», La linguistique 22, pp. 3-46.

MAIDEN, M. (1997): «Inflectional morphology of the noun and adjective», en Maiden, M. y Parry, M. (eds.), The dialects of Italy, Nueva York, Routledge, pp. 68-74.

MAŃCZAK, W. (1958): «Tendences générales des changements analogiques», Lingua 7, pp. 298-325, 387-420.

MARChELlo-Nizia, Ch. (2006): Grammaticalisation et changement linguistique, Bruselas, De Boeck.

MCDaniels, T. (2003): «What's wrong with reanalysis», Toronto Working Papers in Linguistics 21, pp. 81-88.

NARROG, H. (2007): «Exaptation, grammaticalization, and reanalysis», California Linguistic Notes $32 / 1$, pp. 1-25.

Norde, M. (2009): Degrammaticalization, Oxford, Oxford University Press.

Peyraube, A. (2002): «L'évolution des structures grammaticales», Langages 146, pp. $46-58$. 
Plank, F. (2004): «Inevitable reanalysis. From local adpositions to approximative adnumerals, in German and wherever», Studies in Language 28/1, pp. $165-201$.

RAKIČ, S. (2005): «O izbočeniu imena stanovnika gradova i oblasti (-anin: jedan sufiks ili dva?)», Zbornik Matice Sprske za filologiju i lingvistiku 48, pp. 267-275.

Schulte, K. (2008): «Morphology of the eggs, and what can it tell us about Romanian noun inflection», en Bowern, C., Evans, B. y Miceli, L. (eds.), Morphology and language history: In honour of Harold Koch, Ámsterdam-Filadelfia, John Benjamins, pp. 329-339.

Tiersma, P. (1982): «Local and general markedness», Language 58, pp. 832-849.

Timberlake, A. (1977): «Reanalysis and actualization in syntactic change», en Li, Ch. N. (ed.), Mechanisms of syntactic change, Austin-Londres, Texas University Press, pp. 141-177.

Vinogradov, V. A. (1990): «Pererazloženie», en Jarceva, V. N. (ed.), Lingvističeskij ènciklopedičeskij slovar', Moscú, Sovetskaja Ènciklopedia, p. 370.

Vinogradov, V. V. (1972): Russkij jazyk. Grammatičeskoe učenie o slove, 2ª ed., Moscú, Vysšaja škola.

WANNER, D. (2006): The power of analogy. An essay on historical linguistics, Berlín, Mouton de Gruyter.

WILLIS, D. (2007): «Syntactic lexicalization as a new type of degrammaticalization», Linguistics 45, pp. 271-310.

ZALIZNJAK, A. A. $(2002=1967)$ : «O pokazateljax množestvennogo čisla v russkom sklonenii», Russkoe imennoe sklonenie s priloženiem izbrannyx rabot po sovremennomu russkomu jazyku i ob̌̌čemu jazykoznaniju, Moscú, Jazyki slavjanskoj kul'tury, pp. 545-549. 